\title{
Effect of Lubricant Additives on the Oxidation Characteristics of Diesel Engine Particulate Matter
}

\author{
Guangju Xu, Yang Zhao $\mathbb{D}^{\mathbb{D}}$, Mingdi Li $\mathbb{D}$, Yanbin Hu, and Ling Lin \\ School of Automotive Engineering, Changshu Institute of Technology, Changshu 215500, China \\ Correspondence should be addressed to Yang Zhao; 171553404@qq.com
}

Received 1 September 2020; Accepted 2 November 2020; Published 24 November 2020

Academic Editor: Rui Wu

Copyright (c) 2020 Guangju Xu et al. This is an open access article distributed under the Creative Commons Attribution License, which permits unrestricted use, distribution, and reproduction in any medium, provided the original work is properly cited.

\begin{abstract}
Three common lubricant additives, including an antioxidant, detergent, and an antifoamer, were added to diesel fuel to perform a diesel engine bench test. Particulate matter samples underwent thermogravimetric analysis to investigate the effect of lubricant additives on the particulate matter oxidation process, characteristic temperature, and activation energy. The results showed the following. Different lubricant additives result in different variation trends in the thermogravimetric curve of a particulate matter sample by varying the rotating speed and torque. When the rotating speed was stable, as the torque increased, the ignition temperature of the particulate matter of Fuel $\mathrm{C}$ declined rapidly during the initial stage and then increased rapidly. When the torque was stable, as the rotating speed increased, the ignition temperature of the particulate matter of Fuel C increased initially and then declined. The particulate matter of Fuel C had the lowest level of activation energy at approximately $57.89 \mathrm{~J} \cdot \mathrm{mol}^{-1}$. The particulate matter of Fuel A had the highest level of activation energy at approximately $74.10 \mathrm{~J} \cdot \mathrm{mol}^{-1}$. When the fuel has a higher cetane number, the combustion chemical reaction rate is faster and results in a more complete reaction. The active substance contact surface increases, which facilitates particulate matter oxidation.
\end{abstract}

\section{Introduction}

The percentage of a lubricant additive in lubrication oil is approximately $5 \sim 15 \%$. Additives play an important role in improving lubrication oil quality, reducing engine friction and wear, and increasing the service life of lubrication oil. Studies [1-4] have shown that lubrication oil is a major source of diesel engine particulate matter. Emission of soluble particulate matter due to lubrication oil consumption has reached $0.018 \sim 0.036 \mathrm{~g} / \mathrm{kW} \cdot \mathrm{h}$. The combustion of additives in lubrication oil, such as calcium, zinc, and phosphorus, creates $0.0015 \sim 0.0030 \mathrm{~g} / \mathrm{kW} \cdot \mathrm{h}$ of ash emissions, which contributes to approximately $15 \%$ of insoluble particulate matter emissions. Lubricant-based oil undergoes pyrolysis and a dehydrogenation reaction at high temperatures and generates insoluble particulate matter, which contributes to $20 \sim 30 \%$ of all particulate matter emissions.

Researchers worldwide have conducted extensive research on the theoretical relationship between lubrication oil and particulate matter emission/oxidation characteristics. HN Sharma et al. performed thermogravimetric (TG) analysis of diesel engine particulate matter, which was tested under various operating parameters, including the oxygen flow rate, sample mass, oxygen partial pressure, and heating rate [5]; the authors discovered that the oxidation rate of particulate matter decreased with a decrease in heating rate and oxygen flow rate, and the difference in sample mass had an insignificant impact on the particulate matter oxidation activity. DQ Mei et al. calculated the activation energy of the oxidation reaction of diesel engine particulate matter soot via thermogravimetric analysis and discovered that the weightlessness of the particulate matter mass was primarily caused by the soluble organic fraction (SOF) volatilization in the low-temperature zone and soot oxidation in the hightemperature zone, where the proportions in the two thermal zones were approximately $32 \%$ and $63 \%$, respectively [6]. AlQurashi and Boehman compared and analyzed the oxidation characteristics of diesel engine particulate matter under 
different exhaust gas recirculation (EGR) rates via thermogravimetric analysis [7]; the authors discovered that when the EGR rate was $20 \%$, the particulate matter had a low ignition temperature, short burnout time, and more intense oxidation. Man et al. compared the weightlessness rates of diesel engine particulate matter mass at temperatures between 450 and $550^{\circ} \mathrm{C}$ under various conditions [8]; the authors discovered that a low load resulted in a lower particulate matter oxidation rate. Pirjola et al. analyzed the effect of metal elements in lubrication oil on the particulate matter oxidation characteristics by mixing lubrication oil with diesel [9]; the authors discovered that when $2 \%$ lubrication oil was added to diesel, the ignition temperature of the particulate matter was reduced by $150-200^{\circ} \mathrm{C}$, the oxidation rate of the particulate matter increased significantly, and the activation energy reduced slightly, that is, from $108 \mathrm{~kJ} \cdot \mathrm{mol}^{-1}$ to $101 \mathrm{~J} \cdot \mathrm{mol}^{-1}$. A study by Sonntag et al. suggested that the weighted contribution of lubrication oil to light vehicle particulate matter emissions was approximately $25 \%$ [10]. A path tracking result of lubrication oil consumption suggested that, under a partial load, lubrication oil significantly contributes to nanometre-sized particulate matter emissions; when the size of the particulate matter was on the nanometre scale, reducing the phosphorous content additive content of the lubrication oil did not necessarily reduce the amount of nanometre-sized particulate matter emissions from a diesel engine.

However, among the existing literature, there are only a limited number of studies that have investigated the effect of lubricant additives on particulate matter emissions and oxidation characteristics. Therefore, in this paper, three common lubricant additives, including an antioxidant, detergent, and an antifoamer, were added to diesel fuel to perform a diesel engine bench test. Particulate matter samples underwent thermogravimetric analysis to investigate the effect of lubricant additives on the particulate matter oxidation process, characteristic temperature, and activation energy.

\section{Experimental Methodology}

2.1. Experimental Diesel Fuel Preparation Scheme. Three LOAs, namely, an antioxidant (main component: zinc dialkyl phosphorodithioate), a foam inhibitor (main component: dimethylpolysiloxane), and a detergent (main component: high-alkali value synthetic calcium sulfonate), were selected for the experiment. Three experimental fuels were prepared using weight percentages. Each fuel was prepared by adding one of the three LOAs to a certain amount of diesel at a mass ratio of 1:100 (LOA: diesel) and then stirring the mixture homogeneously. Before the start of the experiment, the antioxidant-diesel, foam inhibitor-diesel, and detergent-diesel fuels were allowed to stand for $24 \mathrm{~h}$. No separation between the additive and diesel was observed in any of the fuels.

The antioxidant-diesel, foam inhibitor-diesel, and detergent-diesel fuels are referred to as Fuel A, Fuel B, and Fuel $\mathrm{C}$, respectively, in the following discussions.
2.2. Quality Evaluation of the Experimental Diesel Fuels. Fuel A, Fuel B, and Fuel C were tested using a MINISCAN fuel quality analyzer. The main technical specifications of the analyzer are as follows: measuring range for the cetane number: 20-80; measuring range for total aromatic hydrocarbons: $0-80 \%$; measuring range for polycyclic aromatic hydrocarbons (PAHs): $0-50 \%$; and measuring range for kinematic viscosity: $0-10 \mathrm{~m} / \mathrm{s}\left(40^{\circ} \mathrm{C}\right)$. The testing was based on the partial least-squares method and an advanced chemical model that met the ASTM E1655 standard. Table 1 presents a summary of the test results for the three fuels.

2.3. Experimental Diesel Engine and Test Conditions. The experiment was conducted on a high-pressure common-rail diesel engine. The technical parameters of the diesel engine are as follows: cylinder diameter: $93 \mathrm{~mm}$; piston stroke: $102 \mathrm{~mm}$; displacement: $2.77 \mathrm{~L}$; total power/rotational speed: $85 \mathrm{~kW} / 3,600 \mathrm{r} /$ min; maximum torque/rotational speed: $285 \mathrm{~N} / 2,000 \mathrm{r} / \mathrm{min}$; and compression ratio: 17.2. The test conditions in this paper are shown in Table 2, and the effects of operating parameters such as speed and torque of the diesel engine on the oxidation characteristics of exhaust particulates are evaluated.

2.4. Sample Collection and Pretreatment. The PM sample collection system consists mainly of a sample collection pipe, a vacuum pump, a differential pressure gauge, and a microorifice uniform deposit impactor (MOUDI). During the experiment, diesel exhaust was pumped by the vacuum pump into the MOUDI sample collection system at a constant volume flow rate of $10 \pm 0.5 \mathrm{~L} / \mathrm{min}$. Due to inertia, PM was placed on the aluminum foil $(\varphi 47 \mathrm{~mm})$ on the impact plate and was thus divided into various classes. Before sampling, the aluminum foil filter paper was placed in a drying chamber (humidity: $40 \%$ ) for over $24 \mathrm{~h}$ to balance its temperature and humidity. Then, silica gel was sprayed onto the surface of the filter paper. Afterward, the filter paper was dried in an oven at $600^{\circ} \mathrm{C}$ for $2 \mathrm{~h}$ and subsequently placed in a drying chamber for $24 \mathrm{~h}$. During the sampling process, a U-shaped cooling pipe was used to cool the diesel exhaust to ensure the safe operation of the MOUDI. After sampling, to prevent PM from blocking the orifices and affecting sample collection under the subsequent condition, the orifice disks of various sizes were removed from the MOUDI and immersed in a solution composed of dichloromethane and n-hexane for cleaning and subsequently blown dry using clean compressed air. Figure 1 shows a schematic diagram of the principle of PM impact sampling.

The soluble OM, residual unburned fuel, and some unburned lubricating oil adhering to the surface of the DEPM could easily cause it to aggregate and form blocks, which would affect its micromorphological and structural testing under a high magnification microscope. Therefore, DEPM samples were pretreated [11-13]. The samples were immersed in anhydrous ethanol, an organic solvent, and subjected to oscillation in an ultrasonic oscillator for over $10 \mathrm{~min}$. The well-oscillated samples were then centrifuged at 
TABLE 1: Summary of the test results for the three fuels.

\begin{tabular}{lcccc}
\hline Parameter & Cetane value & Total aromatic hydrocarbon (\%) & Polycyclic aromatic hydrocarbons $(\%)$ & T90 \\
\hline Fuel A & 50.2 & 22.8 & 4.21 & 376.4 \\
Fuel B & 52.7 & 26.1 & 2.37 & 380.1 \\
Fuel C & 53.7 & 27.1 & 2.22 & 371.3 \\
\hline
\end{tabular}

TABLE 2: The test conditions.

\begin{tabular}{lccc}
\hline Test condition & Rotational speed $(\mathrm{r} / \mathrm{min})$ & Torque $(\mathrm{N} \cdot \mathrm{m})$ & Engine test duration $(\mathrm{min})$ \\
\hline 1 & 1200 & 100 & 10 \\
2 & 1200 & 175 & 10 \\
3 & 1200 & 250 & 10 \\
4 & 2000 & 250 & 10 \\
5 & 2800 & 250 & 10 \\
\hline
\end{tabular}

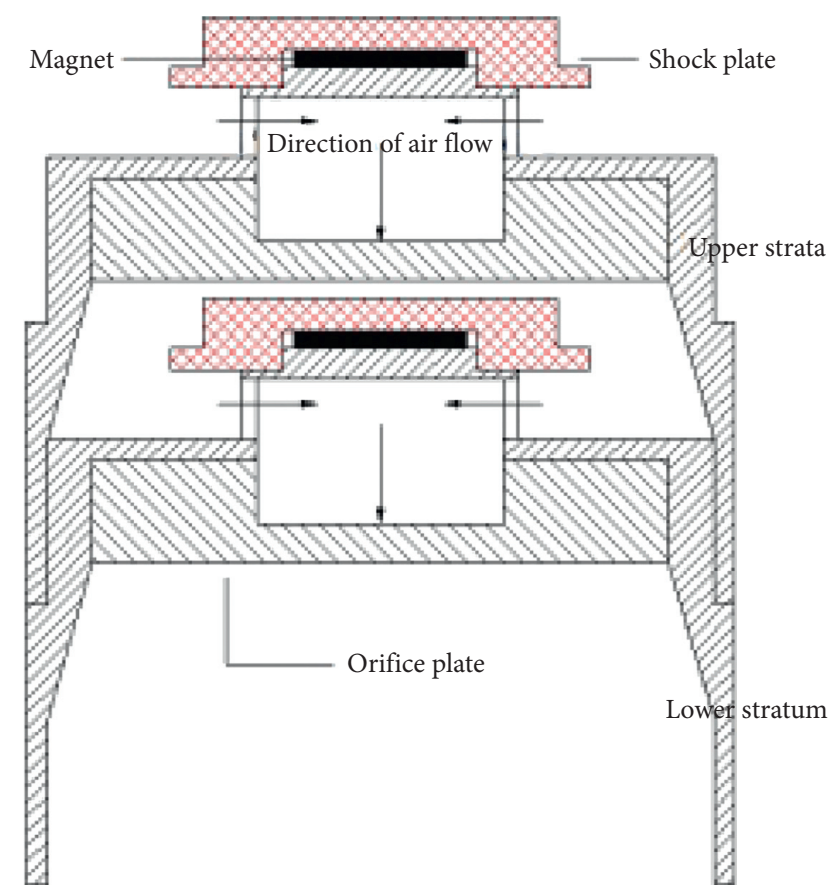

FIGURE 1: Schematic diagram of the principle of PM impact sampling.

a rotational speed no lower than $7,000 \mathrm{r} / \mathrm{min}$ for $5 \mathrm{~min}$. The aforementioned steps were repeated three times. Before testing, the samples were coated with gold to improve their surface conductivity.

2.5. Sample Analysis Equipment. A NETZSCH thermal synchronous heat analyzer (Figure 2) is used to analyze the particle samples by thermogravimetric analysis, and the ignition temperature, the combustion temperature, and the reaction interval of the particles are measured. The main technical specifications of the instrument are as follows: temperature range is RT-1500 degrees C, heating rate is $0-50\left(\mathrm{~min}^{-1}\right)$, enthalpy accuracy is $1 \%$, temperature accuracy is $0.1 \%$, and balance sensitivity is $0.1-1 \mu \mathrm{g}$.

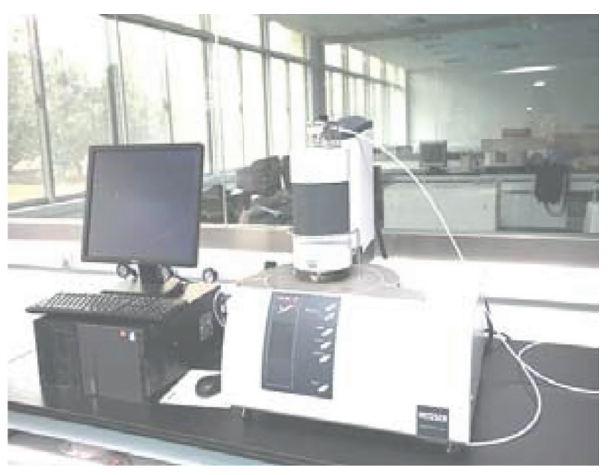

FIGURE 2: Sample analysis equipment.

\section{Results and Discussion}

3.1. Particulate Matter Oxidation Process. Particle oxidation activity refers to the difficulty of particles being oxidized and is usually studied by thermogravimetry [14]. By analyzing the mass change curve in the weight loss process of the particle, the change of the particle sample at different temperatures can be obtained. At the same time, the ignition temperature, the burnout temperature, the apparent activation energy, and other characteristic parameters can be calculated.

Figure 3 shows the thermogravimetric analysis results of particulate matter samples from diesel engine bench tests using three different fuels, that is, Fuel A, Fuel B, and Fuel C, under various rotating speeds and torques. In the thermogravimetric analysis, the initial temperature was $40^{\circ} \mathrm{C}$; the terminating temperature was $750^{\circ} \mathrm{C}$; the heating rate was $15^{\circ} \mathrm{C} / \mathrm{min}$; the reaction gas was nitrogen; and the flow rate was $50 \mathrm{ml} / \mathrm{min}$. Because the particulate matter mass essentially did not change before reaching $250^{\circ} \mathrm{C}$, in this paper, the thermogravimetric curve between 250 and $750^{\circ} \mathrm{C}$ was selected for the analysis.

The curve shows that when the temperature is less than $300^{\circ} \mathrm{C}$, the mass percentage of the particulate matter sample essentially did not change. As the temperature increased continuously, the mass percentage of the particulate matter sample declined gradually. When the temperature reached $650^{\circ} \mathrm{C}$, the mass percentage of the particulate matter sample 


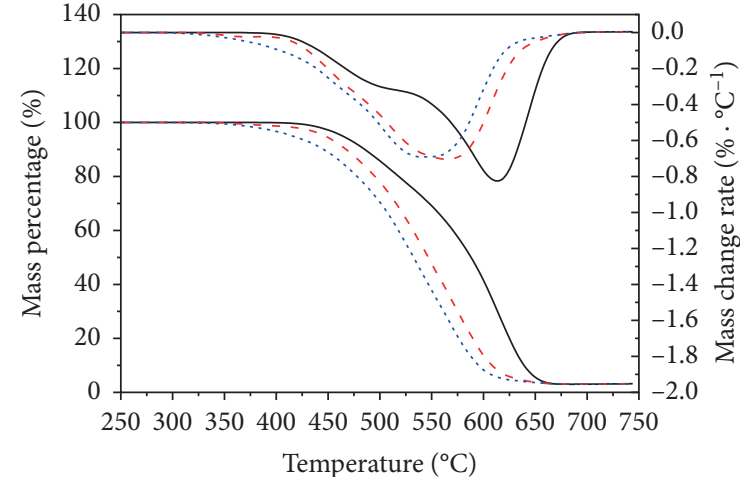

$250 \mathrm{~N} \cdot \mathrm{m}$

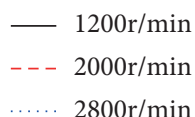

(a)

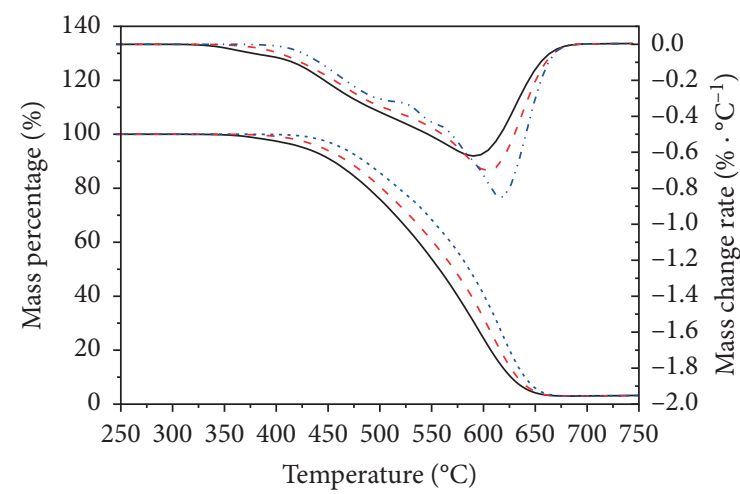

$250 \mathrm{~N} \cdot \mathrm{m}$

- 2800 $\mathrm{r} / \mathrm{min}$

- - 2000r/min

..... $1200 \mathrm{r} / \mathrm{min}$

(c)

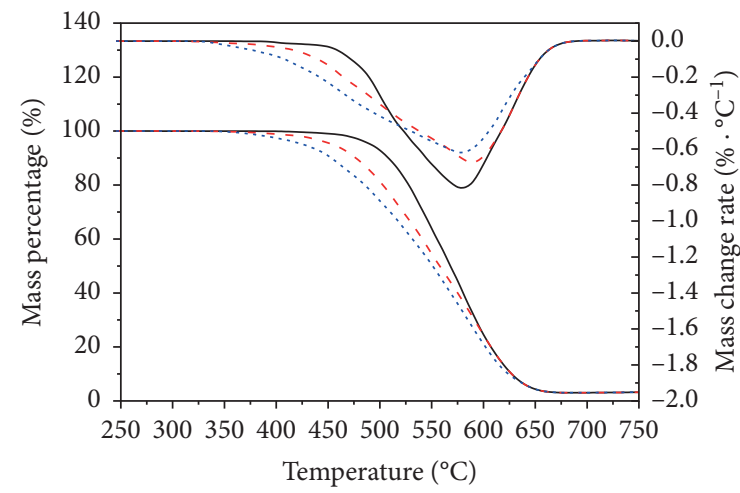

$250 \mathrm{~N} \cdot \mathrm{m}$

- $1200 \mathrm{r} / \mathrm{min}$

- - 2000r/min

..... 2800r/min

(e)

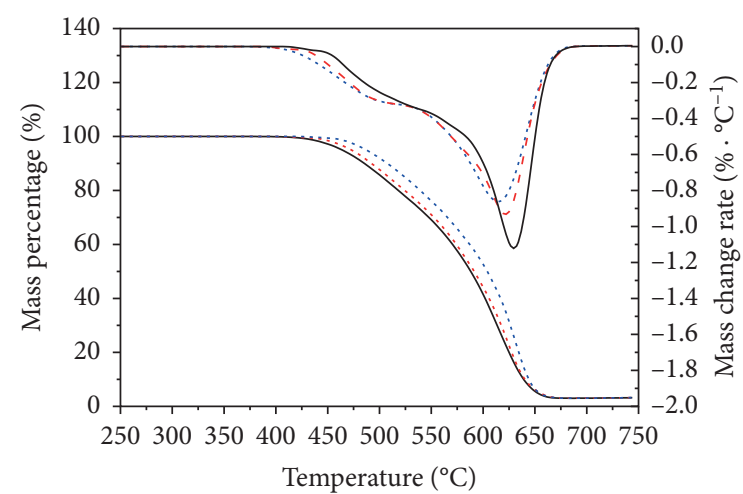

$1200 \mathrm{r} / \mathrm{min}$

$-100 \mathrm{~N} \cdot \mathrm{m}$

_. $175 \mathrm{~N} \cdot \mathrm{m}$

$250 \mathrm{~N} \cdot \mathrm{m}$

(b)

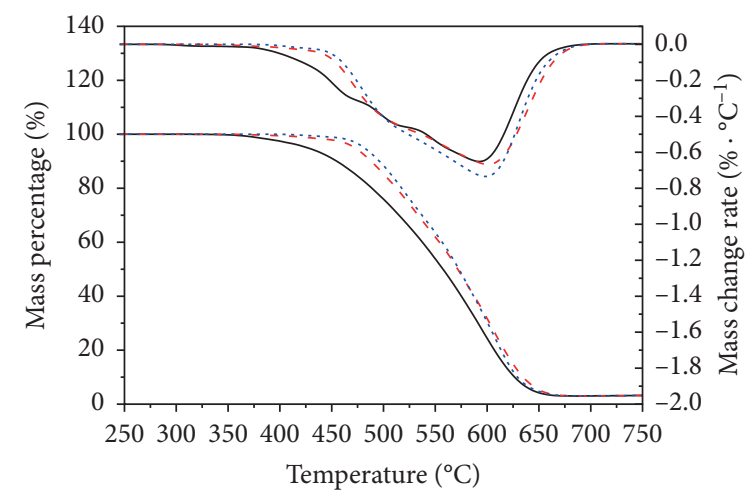

$1200 \mathrm{r} / \mathrm{min}$

- 250N.m

_. - $175 \mathrm{~N} \cdot \mathrm{m}$

..... 100N.m

(d)

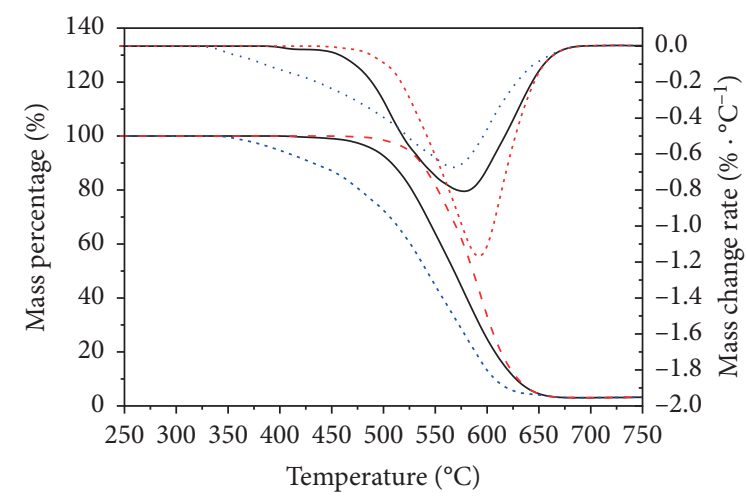

$1200 \mathrm{r} / \mathrm{min}$

$250 \mathrm{~N} \cdot \mathrm{m}$

- - $175 \mathrm{~N} \cdot \mathrm{m}$

… $100 \mathrm{~N} \cdot \mathrm{m}$

FIGURE 3: The thermogravimetric analysis results of particulate matter samples from diesel engine bench tests using three different fuels. (a) Fuel A: rotational speed. (b) Fuel A: torque. (c) Fuel B: rotational speed. (d) Fuel B: torque. (e) Fuel C: rotational speed. (f) Fuel C: torque. 
no longer decreased, and the oxidation process was essentially complete. This process primarily consists of water content evaporation, SOF component volatilization, and soot pyrolysis [15-17]. When different lubricant additives are added, the variations in the thermogravimetric curves of the particulate matter sample versus rotating speed and torque differ. When the diesel engine torque stabilized at $250 \mathrm{~N} \cdot \mathrm{m}$, as the rotating speed increased, the particulate matter TG curve shifted towards the low-temperature zone; when the rotating speed increased, the particulate matter was more likely to be oxidized. When an antioxidant was added, this trend was more conspicuous. Lubrication oil detergent has no significant impact on the particulate matter weightlessness rate. When the temperature was between 350 and $500^{\circ} \mathrm{C}$, the oxidation rate of the particulate matter of Fuel $\mathrm{C}$ increased with rotating speed. After $500^{\circ} \mathrm{C}$, the particulate matter oxidation rate under a low rotation speed exceeded that under a high rotation speed. As the torque increased, the TG curve of the particulate matter of Fuel A shifted slightly towards the right, which means that, under a low rotating speed, when the torque was larger, the particulate matter was less likely to be oxidized. When the torque was $250 \mathrm{~N} \cdot \mathrm{m}$, the particulate matter of Fuel B was more likely to be oxidized. When the torque was $175 \mathrm{~N} \cdot \mathrm{m}$, the particulate matter fuel was most likely to be oxidized. When the temperature exceeded $500^{\circ} \mathrm{C}$, the effect of torque on the particulate matter oxidation rate was inconspicuous. These results show that when a diesel engine is under different operating conditions, the effects of lubricant additives on the particulate matter oxidation characteristics of a diesel engine differ.

3.2. Characteristic Temperature. In the process of thermogravimetric analysis, the particles are evaporated, volatilized, pyrolyzed, and oxidized, and the oxidation reactions of particles in different sources are different [18-20]. In this paper, the characteristic temperature is used to describe the difference of particle oxidation characteristics, and the ignition temperature $\left(T_{i}\right)$, the peak weight loss temperature $\left(T_{p}\right)$, and the burnout of the particles are selected. Temperature $\left(T_{h}\right)$ describes the sensitivity to temperature in the process of particle oxidation.

3.2.1. Ignition Temperature. The particulate matter ignition temperature $\left(T_{i}\right)$ is the temperature of the particulate matter soot when combustion begins. The weightlessness rate at the particulate matter ignition temperature is $-0.1 \%{ }^{\circ} \mathrm{C}^{-1}$.

Figures 4(a) and 4(b) show the ignition temperature of the diesel engine particulate matters of Fuels A, B, and C under various operating conditions. Figure 4(a) shows that when the rotational speed stabilized at $1200 \mathrm{r} / \mathrm{min}$, as the torque increased, the ignition temperatures of the particulate matter of Fuel A and Fuel B gradually declined; the ignition temperature of the particulate matter of Fuel $\mathrm{C}$ declined rapidly during the initial stage and then increased rapidly. When the torque was $175 \mathrm{~N} \cdot \mathrm{m}$, the ignition temperature of the particulate matter of Fuel C was only $382^{\circ} \mathrm{C}$. This may be due to the fact that Fuel $\mathrm{C}$ has the highest cetane value of
53.7, which is easy to ignite and has a high degree of combustion perfection. At the same time, Fuel $\mathrm{C}$ and its particles have the lowest polycyclic aromatic hydrocarbon content, the lowest energy required for particle oxidation, and the lowest ignition temperature. When the torque was $100 \mathrm{~N} \cdot \mathrm{m}$ and $200 \mathrm{~N} \cdot \mathrm{m}$, the ignition temperature of the particulate matter of Fuel $\mathrm{C}$ was approximately $500^{\circ} \mathrm{C}$, which significantly exceeded the values of Fuel $\mathrm{A}$ and Fuel B. Figure 4(b) shows that when the torque was stable, as the rotating speed increased, the ignition temperatures of the particulate matter of Fuel A and Fuel B declined. When the rotating speed was $2800 \mathrm{r} / \mathrm{min}$, the ignition temperature of the particulate matter of Fuel A was approximately $407^{\circ} \mathrm{C}$; the ignition temperature of the particulate matter of Fuel B was approximately $409^{\circ} \mathrm{C}$. As the rotating speed increased, the ignition temperature of the particulate matter of Fuel C increased initially and then declined [21-25]; when the rotating speed was $2000 \mathrm{r} / \mathrm{min}$, the particulate matter ignition temperature reached the peak at approximately $438^{\circ} \mathrm{C}$.

3.2.2. Burnout Temperature. The burnout temperature $\left(T_{h}\right)$ is the temperature at the later stage of high-temperature oxidation when the particulate matter weightlessness rate is $-0.1 \% \cdot{ }^{\circ} \mathrm{C}^{-1}$. Figures $5(\mathrm{a})$ and $5(\mathrm{~b})$ show the burnout temperatures of the diesel engine using the particulate matter of Fuel A, Fuel B, and Fuel C under different operating conditions. Figure 5(a) shows that when the rotating speed was stable, as the torque increased, the burnout temperature of the particular matter of Fuel A exhibited no apparent change; the burnout temperature of the particular matter of Fuel B increased initially and then declined rapidly; the burnout temperature of the particulate matter of Fuel C declined initially and then increased rapidly. When the torque was $100 \mathrm{~N} \cdot \mathrm{m}$, the particulate matter of Fuel A had the highest burnout temperature at approximately $662^{\circ} \mathrm{C}$; the particulate matter of Fuel $\mathrm{C}$ had the lowest burnout temperature at approximately $655^{\circ} \mathrm{C}$. When the torque was $250 \mathrm{~N} \cdot \mathrm{m}$, the particulate matter of Fuel B had the lowest burnout temperature at approximately $656^{\circ} \mathrm{C}$. Figure $5(\mathrm{~b})$ shows that when the torque was stable, as the rotating speed increased, the burnout temperatures of the particulate matters from Fuel A, Fuel B, and Fuel C declined. When the rotating speed was $2800 \mathrm{r} / \mathrm{min}$, the particulate matter of Fuel $\mathrm{B}$ had the highest burnout temperature at approximately $660^{\circ} \mathrm{C}$; the particulate matter of Fuel $\mathrm{C}$ had the lowest burnout temperature at approximately $580^{\circ} \mathrm{C}$.

3.2.3. Weightlessness Rate Peak Temperature. The weightlessness rate peak temperature $\left(T_{p}\right)$ refers to the temperature that corresponds to the weightlessness rate peak.

Figures 6(a) and 6(b) show the weightlessness rate peak temperatures of the diesel engine particulate matter from Fuel A, Fuel B, and Fuel C under various operating conditions. Figure 6(a) shows that when the rotating speed was stable, as the torque increased, the weightlessness rate peak temperatures of Fuel A and Fuel $\mathrm{C}$ declined, the weightlessness rate peak temperature of the particulate matter from Fuel B increased initially and then declined. When the 


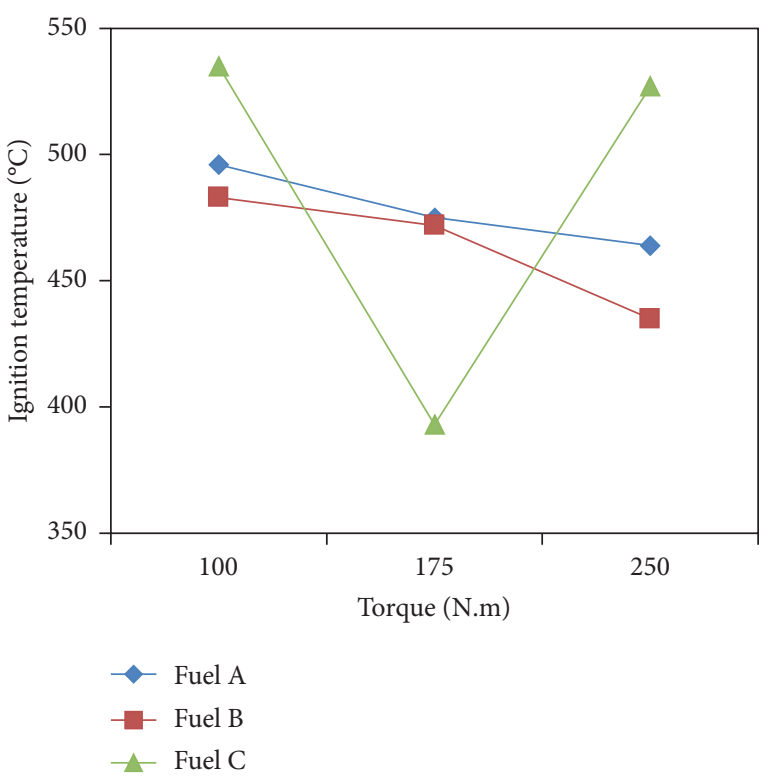

(a)

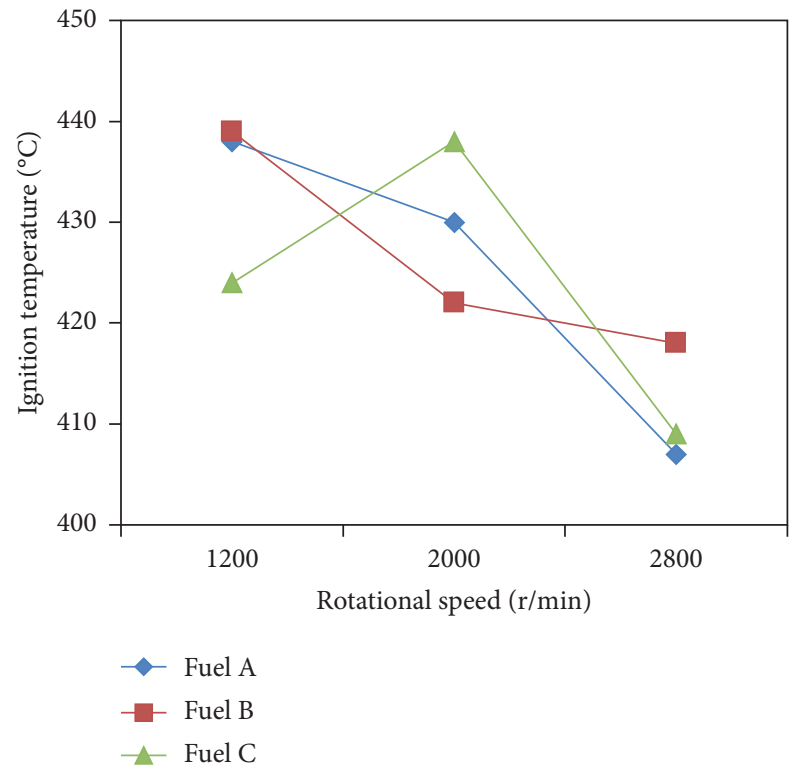

(b)

Figure 4: The ignition temperature of PM under various operating conditions. (a) Different torque. (b) Different rotational speed.

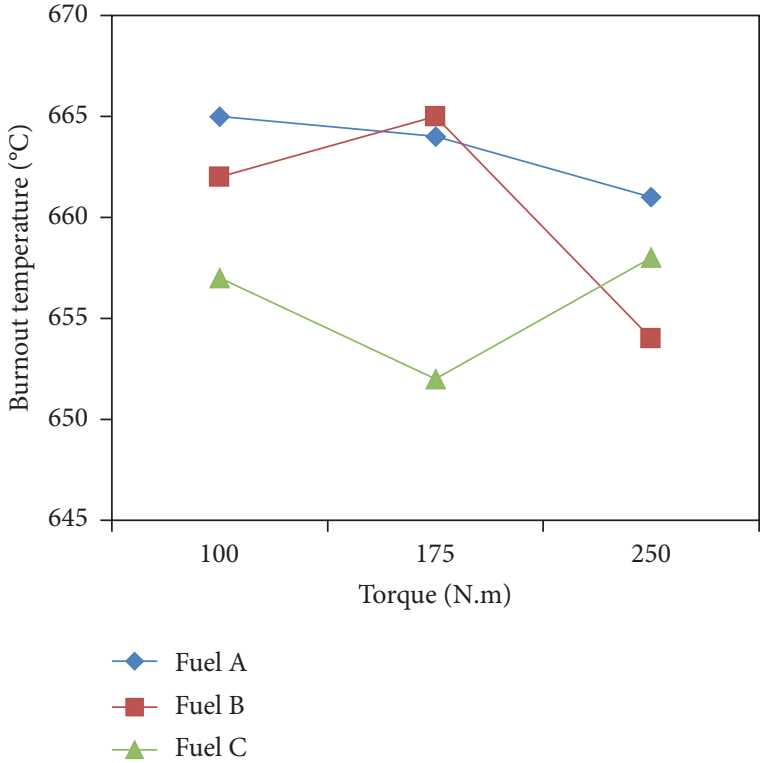

(a)

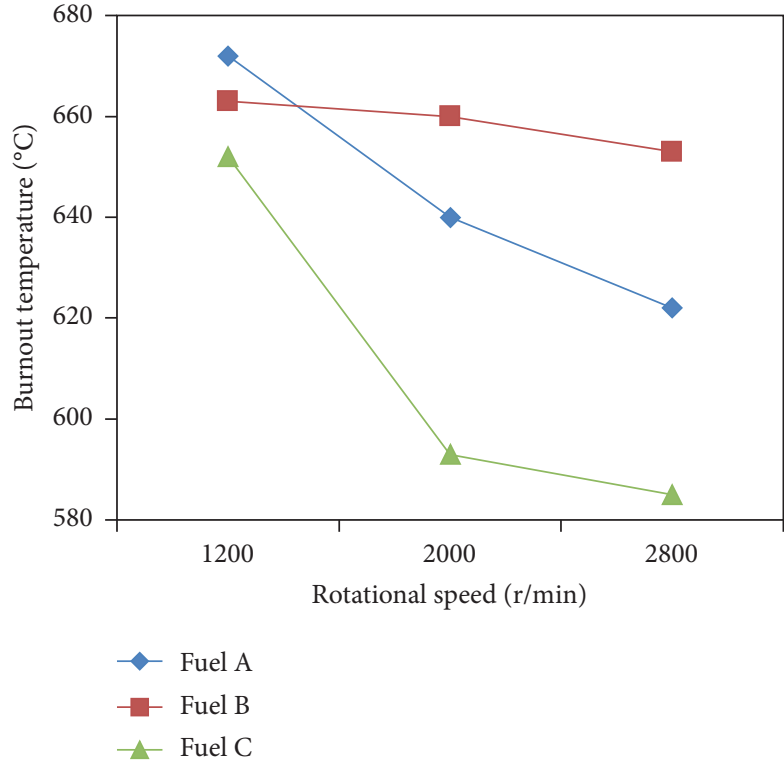

(b)

FIgUre 5: The burnout temperatures of PM under different operating conditions. (a) Different torque. (b) Different rotational speed.

torque was $100 \mathrm{~N} \cdot \mathrm{m}$, the particulate matter of Fuel A had the highest weightlessness rate peak temperature at approximately $630^{\circ} \mathrm{C}$. When the torque was $250 \mathrm{~N} \cdot \mathrm{m}$, the particulate matter of Fuel $\mathrm{C}$ had the lowest weightlessness rate peak temperature at approximately $576^{\circ} \mathrm{C}$. Figure $6(\mathrm{~b})$ shows that when the torque was stable, as the rotating speed increased, the weightlessness rate peak temperatures of the particulate matters of Fuel A and Fuel B declined; the weightlessness rate peak temperature of the particulate matter of Fuel C increased. When the rotating speed was $1200 \mathrm{r} / \mathrm{min}$, the particulate matter of Fuel $\mathrm{C}$ had the lowest weightlessness rate peak temperature at approximately $577^{\circ} \mathrm{C}$. When the rotating speed was $2800 \mathrm{r} / \mathrm{min}$, the particulate matter of Fuel A had the lowest weightlessness rate peak temperature at approximately $531^{\circ} \mathrm{C}$.

3.3. Activation Energy. The activation energy is the minimum energy required for a reactant molecule to become an activated molecule. Higher activation energy indicates that it 


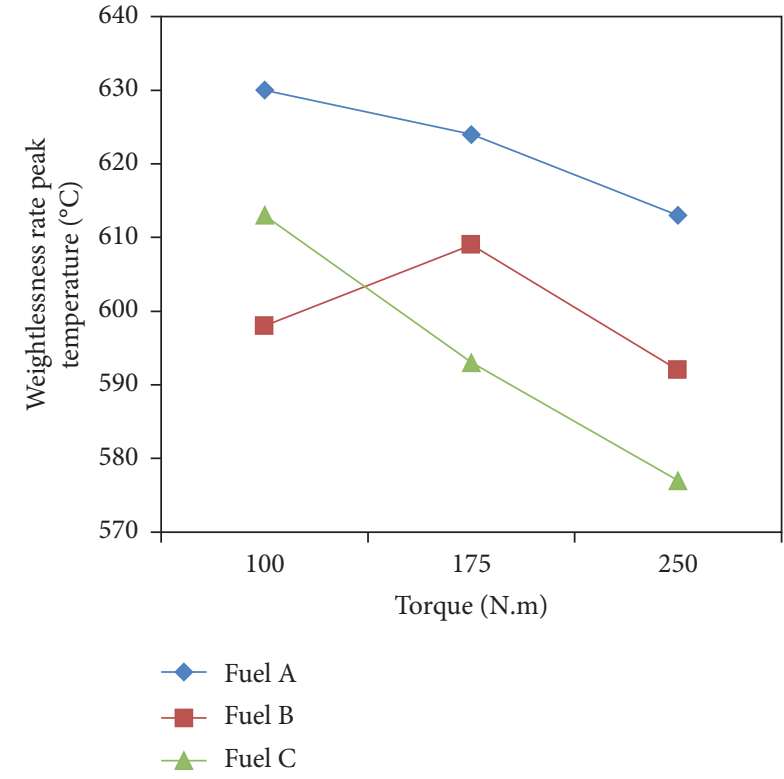

(a)

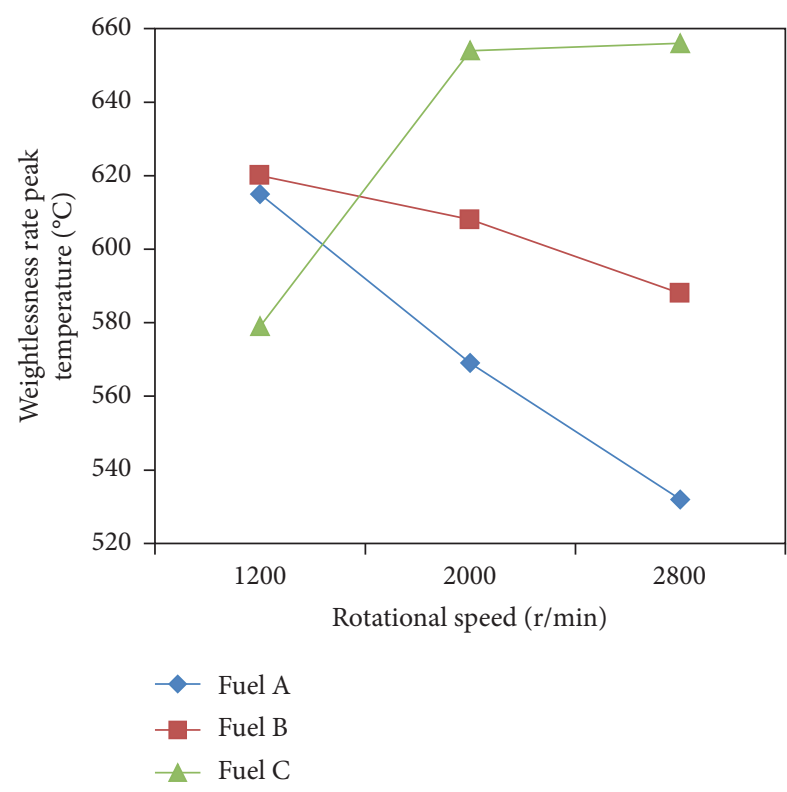

(b)

FIGURE 6: The weightlessness rate peak temperatures of PM under various operating conditions. (a) Different torque. (b) Different rotational speed.

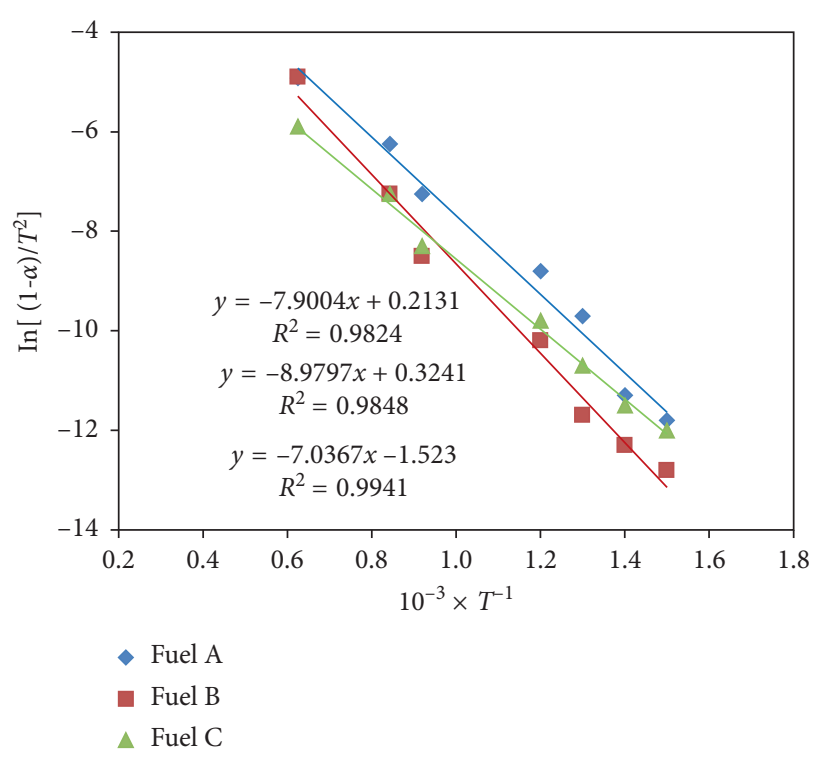

Figure 7: TG curve and fitting equation of particulate matter in $\mathrm{O}_{2}$ atmosphere.

is more difficult for the chemical reaction to proceed. Based on the thermogravimetric analysis (TG and DTG curve), origin curve fitting was performed based on the least square method to obtain a fitting curve of the particulate matter in an $\mathrm{O}_{2}$ atmosphere [26-28], as shown in Figure 7. The results show that the linear regression coefficient of the fitting curve was greater than 0.98 , and thus, the fitting result is accurate. The slope of the fitting line was calculated to determine the activation energy of the particulate matter.
TABle 3: Activation energy of particles.

\begin{tabular}{lcc}
\hline Fuel & Fitting curve equation & Activation energy J.mol ${ }^{-1}$ \\
\hline Fuel A & $Y=-7.9004 x+0.2131$ & 74.10 \\
Fuel B & $Y=-8.9797 x+0.3241$ & 65.44 \\
Fuel C & $Y=-7.0367 x-1.523$ & 57.89 \\
\hline
\end{tabular}

Table 3 lists the calculated activation energy of the particulate matter, which shows that the particulate matter of Fuel $\mathrm{C}$ had the lowest activation energy at approximately $57.89 \mathrm{~J} \cdot \mathrm{mol}^{-1}$, and the particulate matter of Fuel A had the highest activation energy at approximately $74.10 \mathrm{~J} \cdot \mathrm{mol}^{-1}$. The fuel quality analysis result (Table 1) shows that when the fuel cetane number is higher, the combustion chemical reaction rate is faster, the reaction is more complete, and the active substance contact surface increases, which facilitates particulate matter oxidation $[29,30]$.

\section{Conclusions}

The combustion of lubricating oil has a great influence on particulate matter emission of diesel engine. Lubricant additive is the main component of lubricating oil, and the oxidation characteristics of particulate matter directly affect the oxidation regeneration process of posttreatment system. In other words, lubricating oil additives directly affect the efficiency of diesel particulate posttreatment system. Therefore, this paper studies the influence of three commonly used lubricating oil additives on the oxidation characteristics of particulate matter and obtains the following conclusions. 
(1) Different lubricant additives result in different variation trends in the thermogravimetric curve of a particulate matter sample by varying the rotating speed and torque.

(2) When the rotating speed was stable, as the torque increased, the ignition temperature of the particulate matter of Fuel $\mathrm{C}$ declined rapidly during the initial stage and then increased rapidly. When the torque was stable, as the rotating speed increased, the ignition temperature of the particulate matter of Fuel $C$ increased initially and then declined.

(3) When the torque was stable, as the rotating speed increased, the burnout temperatures of the particulate matter of Fuels A, B, and C declined. When the rotating speed was stable and the torque was $100 \mathrm{~N} \cdot \mathrm{m}$, the particulate matter of Fuel A had the highest weightlessness rate peak temperature at approximately $630^{\circ} \mathrm{C}$; when the torque was $250 \mathrm{~N} \cdot \mathrm{m}$, the particulate matter of Fuel $\mathrm{C}$ had the lowest weightlessness rate peak temperature at approximately $576^{\circ} \mathrm{C}$.

(4) When the fuel has a higher cetane number, the combustion chemical reaction rate is faster and results in a more complete reaction. The active substance contact surface increases, which facilitates particulate matter oxidation.

\section{Data Availability}

The data used to support the findings of this study are available from the corresponding author upon request.

\section{Conflicts of Interest}

The authors declare that they have no conflicts of interest.

\section{Acknowledgments}

The authors gratefully acknowledge financial support from National Natural Science Foundation of China (NSFC, 11802039), Natural Science Foundation of Jiangsu Province (BK20160406), and Natural Science Research Project of Jiangsu Higher Education Institutions (18KJB470001).

\section{References}

[1] X. Liang, Y. Wang, G.-Q. Shu, K. Yang, and Y. Chen, "Experimental study the influence of EP antiwear additive on particle emissions in diesel engines," $S A E$ technical paper, vol. 2, 2013.

[2] K. Yehliu, R. L. Vander Wal, O. Armas, and A. L. Boehman, "Impact of fuel formulation on the nanostructure and reactivity of diesel soot," Combust Flame, vol. 159, pp. 3597-3606, 2012.

[3] M. J. Kleeman, S. G. Riddle, M. A. Robert et al., "Lubricating oil and fuel contributions to particulate matter emissions from light-duty gasoline and heavy-duty diesel vehicles," Environmental Science \& Technology, vol. 42, no. 1, pp. 235-242, 2008.
[4] A. K. Singh, "Castor oil-based lubricant reduces smoke emission in two-stroke engines," Industrial Crops \& Products, vol. 33, no. 2, pp. 287-295, 2011.

[5] H. N. Sharma, L. Pahalagedara, A. Joshi et al., "Experimental study of carbon black and diesel engine soot oxidation kinetics using thermogravimetric analysis," Energy \& Fuels, vol. 26, no. 9 , pp. 5613-5625, 2012.

[6] D. Q. Mei, X. Zhao, S. L. Wang et al., "Thermogravimetric characteristics and thermokinetic analysis on PM emission of diesel engine with catalyst," Chinese Internal Combustion Engine Engineering, vol. 34, pp. 37-41, 2013.

[7] K. Al-Qurashi and A. L. Boehman, "Impact of exhaust gas recirculation (EGR) on the oxidative reactivity of diesel engine soot," Combustion \& Flame, vol. 155, no. 4, pp. 675-695, 2008.

[8] X. J. Man, C. S. Cheung, and Z. Ning, "Effect of diesel engine operating conditions on the particulate size, nanostructure and oxidation properties when using wasting cooking oil biodiesel," Energy Procedia, vol. 66, pp. 37-40, 2015.

[9] L. Pirjola, P. Karjalainen, J. Heikkilä et al., "Effects of fresh lubricant oils on particle emissions emitted by a modern gasoline direct injection passenger car," Environmental Science \& Technology, vol. 49, no. 6, pp. 3644-3652, 2015.

[10] D. B. Sonntag, C. R. Bailey, C. R. Fulper et al., "Contribution of lubricating oil to particulate matter emissions from lightduty gasoline vehicles in Kansas City," Environmental Science \& Technology, vol. 46, no. 7, pp. 4191-4199, 2012.

[11] X. Peng, J. Gao, G. Shi et al., "A preliminary assessment of the impacts of multiple temporal-scale variations in particulate matter on its source apportionment," Atmospheric Chemistry \& Physics, pp. 1-40, 2018.

[12] S. Zhou, P. K. Davy, M. Huang et al., "High-resolution sampling and analysis of ambient particulate matter in the Pearl River Delta region of Southern China: source apportionment and health risk implications," Atmospheric Chemistry \& Physics, pp. 1-37, 2018.

[13] W. Wang, J. Yu, Y. Cui et al., "Characteristics of fine particulate matter and its sources in an industrialized coastal city, Ningbo, Yangtze River Delta, China," Atmospheric Research, vol. 203, pp. 105-117, 2018.

[14] A. Yezerets, N. W. Currier, H. A. Eadler et al., "Investigation of the oxidation behavior of diesel particulate matter," $\mathrm{Ca}$ talysis Today, vol. 88, no. 1-2, pp. 17-25, 2003.

[15] C. J. Kamp and B. Andersson, "The role of active sites in the non-catalytic oxidation of carbon particulate matter: a theoretical approach," Topics in Catalysis, vol. 52, no. 13-20, pp. 1951-1956, 2009.

[16] C. Wang, H. Xu, J. M. Herreros et al., "Fuel effect on particulate matter composition and soot oxidation in a directinjection spark ignition (DISI) engine," Energy \& Fuels, vol. 28, no. 3, pp. 2003-2012, 2014.

[17] R. Li and Z. Wang, "Study on status characteristics and oxidation reactivity of biodiesel particulate matter," Fuel, vol. 218, pp. 218-226, 2018.

[18] X. Liu, Y. Yang, F. Yang et al., "Numerical research on the losses characteristic and hot-spot temperature of laminated core joints in transformer," Applied Thermal Engineering, vol. 110, pp. 49-61, 2017.

[19] H. Li, B. Guo, M. Han et al., "Particulate matters pollution characteristic and the correlation between PM (PM, PM) and meteorological factors during the summer in shijiazhuang," Science Bulletin, vol. 6, no. 5, pp. 457-463, 2015.

[20] Y. Lai, Q. Wang, F. Niu et al., "Three-dimensional nonlinear analysis for temperature characteristic of ventilated 
embankment in permafrost regions," Cold Regions Science \& Technology, vol. 38, no. 2-3, pp. 165-184, 2004.

[21] L. Zhang, Y. Ninomiya, and T. Yamashita, "Formation of submicron particulate matter (PM 1) during coal combustion and influence of reaction temperature," Fuel, vol. 85, no. 1011, pp. 1446-1457, 2006.

[22] X. Gao and H. Wu, "Effect of sampling temperature on the properties of inorganic particulate matter collected from biomass combustion in a drop-tube furnace," Energy \& Fuels, vol. 24 , no. 8, pp. 4571-4580, 2010.

[23] H. Kitagawa, T. Iijima, T. Nishizawa et al., "The effect of diethyl carbonate-gas oil mixture fuel on formation of particulate matter and reburning temperature with flow reactor," Jsae Transactions, vol. 41, pp. 1359-1364, 2010.

[24] L. Qu, Z. Wang, and J. Zhang, "Influence of waste cooking oil biodiesel on oxidation reactivity and nanostructure of particulate matter from diesel engine," Fuel, vol. 181, pp. 389395, 2016.

[25] D. R. Oros and B. R. T. Simoneit, "Identification and emission rates of molecular tracers in coal smoke particulate matter," Fuel, vol. 79, no. 5, pp. 515-536, 2000.

[26] X. Tang, H. Lu, L. Lin et al., "Experimental investigation of plasma oxidization of diesel particulate matter," Plasma Chemistry \& Plasma Processing, vol. 33, no. 1, pp. 281-292, 2013.

[27] V. G. Uryadov and E. N. Ofitserov, "Relationship between the cycloaddition activation energy and thermal effect in solutions," Mendeleev Communications, vol. 13, no. 6, pp. 259-260, 2003.

[28] J. B. Gao, M. A. Chao-Chen, S. K. Xing et al., "Thermogravimetric characteristics of particulate matter emitted from a diesel engine equipped with a non-thermal plasma equipment," Transactions of Beijing Institute of Technology, vol. 37, no. 5, pp. 446-450, 2017.

[29] P. Karin and K. Hanamura, "DMicroscopic visualization of PM trapping and regeneration in a diesel particulate catalystmembrane filter (DPMF)," Transactions of Society of Automotive Engineers of Japan, vol. 41, pp. 103-108, 2009.

[30] G. J. Xu, Y. Zhao, M. D. Li et al., "Effects of Lubricating Oil Additives on the Microphysical Properties of Diesel Exhaust Particulate Matter," Combustion Science and Technology, no. 2, pp. 1-16, 2020. 